\title{
Mild fetal cerebral ventriculomegaly as a prenatal sonographic marker for Kartagener syndrome
}

\author{
Marja W. Wessels ${ }^{1,2} *$, Nicolette S. den Hollander ${ }^{2,3}$ and Patrick J. Willems ${ }^{4}$ \\ ${ }^{1}$ Department of Clinical Genetics, Erasmus University Medical Centre, Rotterdam, The Netherlands \\ ${ }^{2}$ Department of Obstetrics and Gynaecology, Erasmus University Medical Centre, Rotterdam, The Netherlands \\ ${ }^{3}$ Department of Clinical Genetics, Leiden University Medical Centre, Leiden, The Netherlands \\ ${ }^{4}$ Synergene NV, Mechelen, Belgium
}

\begin{abstract}
Primary ciliary dyskinesia (PCD), also referred to as immotile-cilia syndrome or Kartagener syndrome, is a group of genetic disorders caused by defective cilia leading to chronic sinupulmonary infection, situs inversus and reduced fertility. Some PCD patients also have cerebral ventriculomegaly or hydrocephalus.

We report here two fetuses and one newborn with mild cerebral ventriculomegaly and a suspected and/or confirmed diagnosis of PCD. These cases demonstrate that mild fetal cerebral ventriculomegaly can be a prenatal sonographic marker of PCD, certainly in fetuses with situs inversus or a history of a previous sib with PCD. Copyright (C) 2003 John Wiley \& Sons, Ltd.

KEY WORDS: fetal cerebral ventriculomegaly; Kartagener syndrome; primary ciliary dyskinesia (PCD); prenatal diagnosis
\end{abstract}

\section{INTRODUCTION}

Primary ciliary dyskinesia (PCD) or immotile-cilia syndrome is a genetically heterogeneous disease with an estimated incidence of 1 in 20.000 to 60.000 live births (Afzelius, 1976; Afzelius et al., 2001). PCD is characterized by recurrent or chronic sinupulmonary infections including sinusitis, rhinitis and bronchitis, which eventually leads to bronchiectasis. The infections are caused by dysmotility, immotility or the absence of cilia. Cilia are normally present on the epithelia lining the sinuses and the respiratory tract where they are responsible for the drainage of foreign particles and microorganisms. Reduced fertility is often present in PCD, certainly in male patients, as cilia are also present on the epithelia of the female oviduct and the male vas deferens. Approximately half of the PCD patients present with situs inversus, in which case PCD is referred to as Kartagener syndrome (KS). Situs inversus in PCD has been suggested to be the consequence of defective monocilia that are normally present on cells of the embryonic node. These cilia are thought to be instrumental in the embryonic movement of organs and the establishment of the left-right body axis (Nonaka et al., 1998; Brueckner, 2001; Hackett, 2002). PCD might therefore cause a random situs with situs inversus in half of the patients. Occasionally, PCD patients also show hydrocephalus or mild enlargement of the cerebral ventricular system and sulci (Greenstone et al., 1984; Jabourian et al., 1986; De Santi et al., 1990; Picco et al., 1993). Also, the chronic headaches occurring in some PCD patients might be related to abnormalities in liquor circulation (Afzelius et al., 2001). The association of PCD with

*Correspondence to: Marja W. Wessels, Department of Clinical Genetics, Erasmus University Medical Centre, Westzeedijk 112, 3016 AH Rotterdam, The Netherlands.

E-mail: wessels@kgen.azr.nl cerebral ventriculomegaly or overt hydrocephalus has also been described in dogs (Edwards et al., 1989; Dhein et al., 1990; Daniel et al., 1995), Wic-Hyd rats (Torikata et al., 1991; Shimizu and Koto, 1992; Nakamura and Sato, 1993), Hpy/Hpy mice (Bryan, 1983), mice with targeted disruption of the foxjl gene (Chen et al., 1998) and mice with an insertional mutation in the axonemal dynein heavy-chain gene, Mdnah5 (Ibañez-Tallon et al., 2002). This suggests a functional role in liquor circulation for the cilia lining the ventricular ependyma of the brain and spinal cord in humans and other species.

Prenatal diagnosis of PCD is sometimes possible by mutation analysis of one of the genes currently known to be involved in PCD (Pennarun et al., 1999; Guichard et al., 2001; Olbrich et al., 2002). However, in the majority of cases, fetal ultrasound examination is the only method to detect PCD prenatally, if at least detectable structural anomalies such as situs inversus are present. However, half of the patients with PCD do not show situs inversus. As ventriculomegaly or hydrocephalus is sometimes present in neonates or children with PCD, it might offer an additional prenatal sonographic marker for PCD.

We present here two fetuses and one newborn with a suspected and/or confirmed diagnosis of PCD presenting with mild cerebral ventriculomegaly.

\section{CASE REPORTS}

\section{Family 1}

The healthy parents of family 1 were of Caucasian descent and unrelated (Figure 1). They were referred to our centre for prenatal diagnosis in their third pregnancy because of a previous child (II-2) with a primum atrial septal defect, aortic isthmus stenosis, absent right superior vena cava and a persistent left superior and 
Family 1

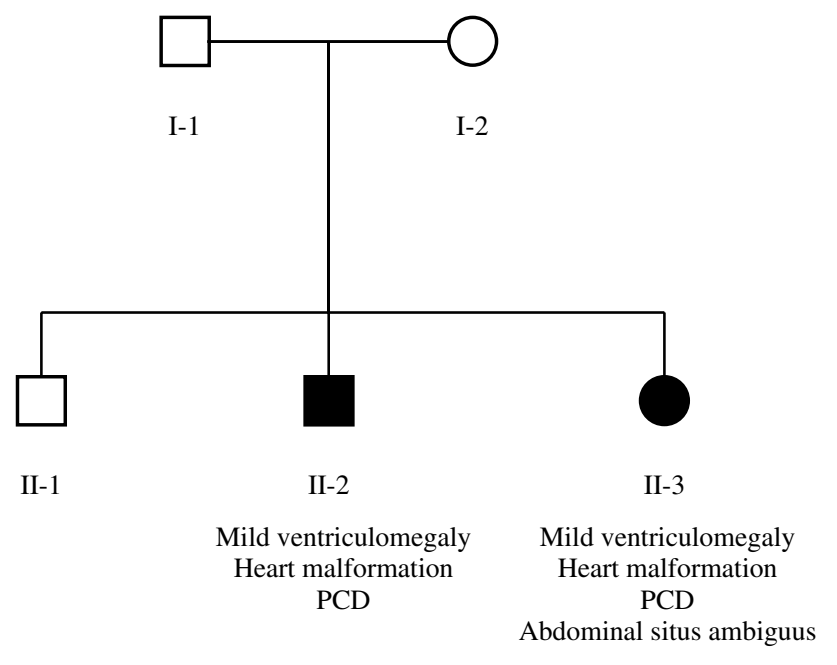

Family 2

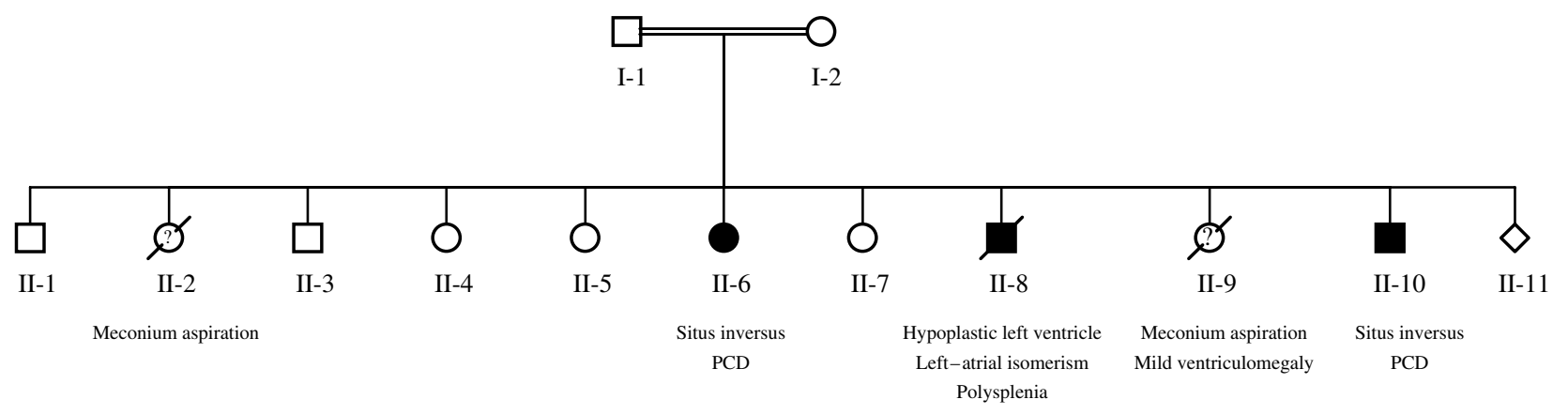

Figure 1-Family pedigrees of the two families with an association of PCD and fetal cerebral ventriculomegaly. Note the variability of the clinical picture

inferior vena cava connected to the coronary sinus. The congenital heart malformations did not necessitate surgical repair. Case II-2 had recurrent atelectases of the right lung and mildly dilated lateral cerebral ventricles in the neonatal period, both of which disappeared later on. However, he had frequent upper-airway infections during his childhood. Occipitofrontal circumference and mental development were normal at the age of five years. The diagnosis of PCD was not made until a suspicion of PCD in the next pregnancy. In that pregnancy (II-3), a fetal anomaly scan at 19 weeks revealed a right-sided stomach and a central liver, a primum atrial septal defect and a persistent left superior vena cava. There also existed mild cerebral ventriculomegaly, with the width of the posterior horn of the lateral ventricle measuring $13 \mathrm{~mm}$ (normal upper limit: $10 \mathrm{~mm}$ ). Amniocentesis revealed a normal female karyotype, and a 22q11 deletion was excluded. PCD was suspected in sib II-2 in view of these ultrasound abnormalities and the presence of similar features with frequent upperairway infections. After counselling, the parents decided to continue the pregnancy. At 37 weeks, a girl weighing $2750 \mathrm{~g}$ was born with Apgar scores of $6\left(1^{\prime}\right)$ and $8\left(5^{\prime}\right)$. The prenatally diagnosed cardiac abnormalities were confirmed, and in addition an absent inferior vena cava with azygous continuation was found. Abdominal abnormalities included a right-sided stomach, septated spleen with a small accessory spleen, central position of the liver with drainage of the left hepatic veins into a persistent left inferior vena cava and intestinal malrotation with volvulus. The child suffered from respiratory difficulties, and atelectases of the lung developed. An ultrasound of the brain made in the first week of life showed cerebral ventricles within the normal size range. In view of the combination of cardiac and abdominal features compatible with a situs abnormality, neonatal lung atelectases and fetal and/or neonatal cerebral ventriculomegaly in one or both sibs, the diagnosis of PCD was suspected. Electron-microscopic examination of a nasal biopsy showed ciliary aplasia in both infants (II2 and II-3), confirming the diagnosis of PCD. The first child (II-1) and the parents were healthy, but were not further investigated.

\section{Family 2}

A consanguineous couple (first cousins) of Moroccan descent was referred in the 10th pregnancy to our centre for prenatal diagnosis because of a previous child (II -6) with KS (Figure 1). The second child (II-2) died on day 2 after birth because of meconium aspiration, but 
no prenatal or post-natal examination was performed. The sixth child (II-6), a girl, had situs inversus totalis and frequent upper-airway infections. This lead to the diagnosis of KS at the age of one month. This diagnosis of PCD was confirmed by nasal and bronchial biopsies showing impaired ciliary motility and abnormal cilia. Electron-microscopic evaluation revealed strongly abnormal cilia with deficiency of the inner dynein arms, radial spokes and nexin links. In the eighth pregnancy, a fetal anomaly scan at 16 weeks of gestation revealed hypoplasia of the left cardiac ventricle (II-8). Cerebral anatomy and thoracic and abdominal situs were normal. Amniocentesis revealed a normal male karyotype. The pregnancy was terminated, and the hypoplasia of the left ventricle was confirmed at autopsy. Additionally, left-atrial isomerism and polysplenia were found. At that time, the diagnosis of PCD was not made. In the ninth pregnancy, ultrasound examination of the fetus (II-9) revealed a normal situs but mild cerebral ventriculomegaly, with the width of the posterior horn of the lateral ventricle measuring $13 \mathrm{~mm}$. Amniocentesis was performed and a normal female karyotype was found. Virological studies on maternal blood were normal. A girl with a birth weight of $3535 \mathrm{~g}$ was born at term. Apgar scores were $3\left(1^{\prime}\right)$ and $6\left(5^{\prime}\right)$, respectively. The child suffered from severe respiratory insufficiency due to meconium aspiration, and atelectases of the right middle lung lobe developed. She died after one day. No further diagnostic workup was performed.

A fetal anomaly scan in the 19th week of the 10th pregnancy (II-10) revealed situs inversus totalis. In view of these abnormalities and the presence of KS in II-6, the tentative prenatal diagnosis of PCD was made in II-10. The fetal cerebral ventricular width was normal. The parents decided to continue the pregnancy. II-10 was born at 41 weeks of gestation with a birthweight of $3640 \mathrm{~g}$, and was hospitalised because of meconium aspiration and respiratory distress. The diagnosis of KS was confirmed by a nasal biopsy showing absent ciliary motility. The child was discharged from the hospital after 6 weeks. He had recurrent lung atelectases in the neonatal period, and upper-airway infections later on.

In retrospect, it is very likely that apart from II6 and II-10, the fetus with hypoplastic left ventricle and left-atrial isomerism (II-8), and possibly the child with mild ventriculomegaly and post-natal respiratory distress (II-9), had PCD. The parents and the other children were reported to be healthy, but no further studies were performed.

\section{DISCUSSION}

We describe here two families with probable autosomal recessive PCD associated with mild ventriculomegaly. In the first family, both sibs affected with PCD had mild dilatation of the lateral cerebral ventricles. In the second family, PCD was suspected in two sibs, of which one showed mild fetal ventriculomegaly, and was confirmed in two additional sibs. In all three cases, cerebral ventriculomegaly was mild, and was only retrospectively recognised to be a part of PCD. The ventricular dilatation in PCD is probably due to a dysfunction of the cilia that line the ventricular ependyma of the brain and spinal cord. It has not only been described in humans but also in dogs, rats and mice with PCD. Consequently, the beating of these cilia must be important in the circulation of liquor. Mild fetal ventriculomegaly can be caused by many factors leading to parenchymal loss of abnormal cerebrospinalfluid circulation. When diagnosed, additional prenatal tests (amniocentesis for karyotyping and virological studies, maternal platelet counts and virology) should be performed. As illustrated here, attention should also be paid to organ situs and structural heart defects in order to exclude PCD, certainly when a history of PCD in a previous child is present. Therefore, mild cerebral ventriculomegaly might be an early sign of PCD. This is important as PCD might be responsible for neonatal difficulties due to respiratory distress and/or meconium aspiration (Monnet, 1978; Whitelaw et al., 1981; Losa et al., 1995), or intestinal malrotation and/or congenital heart defects in case of situs ambiguus. To our knowledge, PCD has never been reported in postnatal follow-up studies of fetuses with mild cerebral ventriculomegaly (Bromley et al., 1991; Bloom et al., 1997; Vergani et al., 1998; Pilu et al., 1999; Mercier et al., 2001; Kelly et al., 2001), probably because PCD is not always recognised in the neonatal period (Losa et al., 1995), particularly not in the absence of situs inversus. This highlights the importance of a thorough diagnostic evaluation of fetal and neonatal abnormalities. Furthermore, a careful family history can lead to an etiologic diagnosis that was not considered in individual affected family members, certainly in diseases with a clinical spectrum as variable as that of PCD.

\section{ACKNOWLEDGEMENTS}

We are grateful to Prof. Dr M.F. Niermeijer and Prof. Dr J. W. Wladimiroff for their valuable comments on the manuscript.

\section{REFERENCES}

Afzelius BA. 1976. A human syndrome caused by immotile cilia Science 193: 317-319.

Afzelius BA, Mossberg B, Bergstrom SE. 2001. Immotile cilia syndrome (primary ciliary dyskinesia), including Kartagener syndrome. In The Metabolic and Genetic Bases of Inherited Disease (8th edn), Scriver C, Beaudet A, Sly W, Valle D, et al. (eds). McGraw-Hill: New York; 4817-4827.

Bloom SL, Bloom DD, DellaNebbia C, Martin LB, Lucas MJ, Twickler DM. 1997. The developmental outcome of children with antenatal mild isolated ventriculomegaly. Obstet Gynecol 90: 3-97.

Bromley B, Frigoletto Jr FD, Benacerraf BR. 1991. Mild fetal lateral cerebral ventriculomegaly: clinical course and outcome. Am J Obstet Gynecol 164: 863-867.

Brueckner M. 2001. Cilia propel the embryo in the right direction. Am J Med Genet 15: 339-344.

Bryan JH. 1983. The immotile cilia syndrome. Mice versus man. Virchows Arch A Pathol Anat Histopathol 399: 65-75.

Chen J, Knowles HJ, Hebert JL, Hackett BP. 1998. Mutation of the mouse hepatocyte nuclear factor/forkhead homologue 4 gene results 
in an absence of cilia and random left-right asymmetry. J Clin Invest 102: $1077-1082$.

Daniel GB, Edwards DF, Harvey RC, Kabalka GW. 1995. Communicating hydrocephalus in dogs with congenital ciliary dysfunction. Dev Neurosci 17: 230-235.

De Santi MM, Magni A, Valletta EA, Gardi C, Lungarella G. 1990. Hydrocephalus, bronchiectasis, and ciliary aplasia. Arch Dis Child 65: $543-544$.

Dhein CR, Prieur DJ, Riggs MW, Potter KA, Widders PR. 1990. Suspected ciliary dysfunction in Chinese Shar Pei pups with pneumonia. Am J Vet Res 51: 439-446.

Edwards DF, Kennedy JR, Patton CS, Toal RL, Daniel GB, Lothrop CD. 1989. Familial immotile-cilia syndrome in English springer spaniel dogs. Am J Med Genet 33: 290-298.

Greenstone MA, Jones RW, Dewar A, Neville BG, Cole PJ. 1984. Hydrocephalus and primary ciliary dyskinesia. Arch Dis Child 59: 481-482.

Guichard C, Harricane MC, Lafitte JJ, et al. 2001. Axonemal dynein intermediate-chain gene (DNAI1) mutations result in situs inversus and primary ciliary dyskinesia (Kartagener syndrome). Am J Hum Gene 68: 1030-1035.

Hackett BP. 2002. Formation and malformation of the vertebrate leftright axis. Curr Mol Med 2: 39-66.

Ibañez-Tallon I, Gorokhova S, Heintz N. 2002. Loss of function of axonemal dynein Mdnah5 causes primary ciliary dyskinesia and hydrocephalus. Hum Mol Genet 11: 715-721.

Jabourian Z, Lublin FD, Adler A, Gonzales C, Northrup B, Zwillenberg D. 1986. Hydrocephalus in Kartagener's syndrome. Ear Nose Throat J 65: 468-472.

Kelly EN, Allen VM, Seaward G, Windrim R, Ryan G. 2001. Mild ventriculomegaly in the fetus, natural history, associated findings and outcome of isolated mild ventriculomegaly: a literature review. Prenat Diagn 21: 697-700.

Losa M, Ghelfi D, Hof E, Felix H, Fanconi S. 1995. Kartagener syndrome: an uncommon cause of neonatal respiratory distress? Eur J Pediatr 154: 236-238.

Mercier A, Eurin D, Mercier PY, Verspyck E, Marpeau L, Marret S. 2001. Isolated mild fetal cerebral ventriculomegaly: a retrospective analysis of 26 cases. Prenat Diagn 21: 589-595.
Monnet P. 1978. Situs inversus and long-term bronchopneumopathies, existing since the neonatal period. Arch Fr Pediatr 35: 607-619.

Nakamura Y, Sato K. 1993. Role of disturbance of ependymal ciliary movement in development of hydrocephalus in rats. Childs Nerv Syst 9: 65-71.

Nonaka S, Tanaka Y, Okada Y, et al. 1998. Randomization of leftright asymmetry due to loss of nodal cilia generating leftward flow of extraembryonic fluid in mice lacking KIF3B motor protein. Cell 95: $829-837$.

Olbrich H, Haffner K, Kispert A, et al. 2002. Mutations in DNAH5 cause primary ciliary dyskinesia and randomization of left-right asymmetry. Nat Genet 30: 143-144.

Pennarun G, Escudier E, Chapelin C, et al. 1999. Loss-of-function mutations in a human gene related to chlamydomonas reinhardtii dynein IC78 result in primary ciliary dyskinesia. Am J Hum Genet 65: $1508-1519$.

Picco P, Leveratto L, Cama A, et al. 1993. Immotile cilia syndrome associated with hydrocephalus and precocious puberty: a case report. Eur J Pediatr Surg 3(Suppl. 1): 20-21.

Pilu G, Falco P, Gabrielli S, Perolo A, Sandri F, Bovicelli L. 1999. The clinical significance of fetal isolated cerebral borderline ventriculomegaly: report of 31 cases and review of the literature. Ultrasound Obstet Gynecol 14: 320-326.

Shimizu A, Koto M. 1992. Ultrastructure and movement of the ependymal and tracheal cilia in congenitally hydrocephalic WICHyd rats. Childs Nerv Syst 8: 25-32.

Torikata C, Kijimoto C, Koto M. 1991. Ultrastructure of respiratory cilia of WIC-Hyd male rats. An animal model for human immotile cilia syndrome. Am J Pathol 138: 341.

Vergani P, Locatelli A, Strobelt N, et al. 1998. Clinical outcome of mild fetal ventriculomegaly. Am J Obstet Gynecol $\mathbf{1 7 8}$ $218-222$.

Whitelaw A, Evans A, Corrin B. 1981. Immotile cilia syndrome: a new cause of neonatal respiratory distress. Arch Dis Child 56: $432-435$. 